\title{
PUBLIC HEALTH RESEARCH
}

\section{Effectiveness of Phone Reminders to Improve Adherence to Anti- Retroviral Therapy: A Meta-Analysis}

\author{
Abdullah Aliff Abdul Wahab, Rosnah Ismail*, Halim Ismail and Nazarudin Safian \\ Department of Community Health, University Kebangsaan Malaysia Medical Centre (UKMMC), Faculty of \\ Medicine, Universiti Kebangsaan Malaysia, Cheras Kuala Lumpur, Malaysia. \\ *For reprint and all correspondence: Assoc. Prof. Dr Rosnah Ismail, Department of Community Health, \\ University Kebangsaan Malaysia Medical Centre (UKMMC), Faculty of Medicine, Universiti Kebangsaan \\ Malaysia, Cheras Kuala Lumpur, Malaysia. \\ Email:drrose@ppukm.ukm.edu.my
}

ABSTRACT

\begin{tabular}{ll}
\hline Introduction & Adherence to anti-retroviral therapy (ART) regimens remains a difficult issue. \\
Methods & Thus, it was hoped that the use of phone reminders would improve adherence. \\
& The Cochrane database was searched using selected keywords for this meta- \\
& analysis. We included randomised, controlled trials (RCTs) that utilised \\
& interventions with phone reminder and reported adherence outcomes, as the \\
& proportion of prescribed pills taken, the scores on an adherence questionnaire, \\
& or the follow-up rate. Two independent authors screened titles of article for \\
& inclusion, extracted the relevant data, and assessed articles for risk of bias. \\
& Seven RCTs published between 2010 and 2017 were selected for inclusion in \\
this review. The sample size ranged from 76 to 631 participants. Most RCTs \\
Results & used short message service (SMS) and phone call reminders as interventions. \\
& The rate of adherence was $1.17-$ fold greater among those who received phone \\
& reminders than those who did not, which was statistically significant (Z=2.86, \\
& p $=0.004)$. Those who received phone reminders showed a $17 \%$ higher \\
& likelihood for adherence compared with those who did not receive any phone \\
reminder interventions. \\
Phone reminders remain significantly effective means for improving \\
adherence. \\
Anti-Retroviral Agents - Cell Phone- Smartphone - Compliance - Medication \\
Adherence.
\end{tabular}

Article history:

Received: 24 November 2020

Accepted: June 2021

Published: 1 September 2021 


\section{INTRODUCTION}

Human immunodeficiency virus (HIV), and the associated development of acquired immunodeficiency syndrome (AIDS), has caused 32 million deaths, globally. Regionally, two-thirds of worldwide HIV incidence occurred in the African region, where, as of 2017, nearly 26 million HIVaffected individuals reside. ${ }^{1}$ Although since year 2012, the World Health Organization (WHO) ${ }^{2}$ introduced the theme "Getting to Zero: Zero new Human Immunodeficiency Virus (HIV) infections, Zero deaths from AIDS-related illness and Zero discrimination" during World AIDS Day, the disease remains a serious public health problem.

The first anti-retroviral therapy (ART) tested in clinical trials was azidothymidine (AZT), which was later called zidovudine (ZDV). Starting in 1987, ZDV was approved for use in patients, but only those with advanced-stage HIV. Today, many types of ARTs are available, ranging from the traditional classes [nucleoside reverse transcriptase inhibitors (NRTIs), non-NRTIs, and protease inhibitors] and newer classes (entry/attachment inhibitors and integrase inhibitors). ${ }^{3}$

Adherence to ART regimens remains a problem, due to high costs and long periods of follow-up. The $\mathrm{WHO}^{4}$ defines adherence as "the extent to which a person's behaviour - taking medication, following a diet, and/or executing lifestyle changes, corresponds with agreed recommendations from a health care provider". A great deal of evidence is available on the benefits of adherence to recommended ART regimens among those affected by HIV. For example, a randomised, controlled trial (RCT) found that the early initiation of ART reduced the risk of HIV-transmission among serodiscordant couples by $96 \% .^{5}$ Furthermore, adherence may be closely related to the infectivity of HIV because increased viral shedding inside the genital compartment can occur due to poor adherence, increasing infectivity. ${ }^{6,7}$

The WHO found that phone reminders were among the most popular types of ART adherence interventions being studied for effectiveness, in addition to cognitive-behavioural interventions, education, treatment supporter, and directly observed therapies. More than $16 \%$ of the studies included in this review studied the effectiveness of intervention methods, although these studies yielded conflicting results. ${ }^{8}$ In the present meta-analysis, we limited our review to clinical trials that studied phone reminders as interventions, and those that reported the outcome, in terms of ART adherence. The most recent metaanalysis focusing on this topic was done in 2012 , more than five years ago. Interestingly, a study found that weekly mobile phone text-messaging was an effective method for improving adherence to ART when compared with standard care alone. ${ }^{9}$ The technological landscape has changed tremendously during the past five years and hence, this review provides an updated synthesis of the body of knowledge regarding whether phone reminders remain an effective intervention for improving adherence to ART regimens among patients with HIV.

\section{METHODS}

We conducted this review in accordance with the Cochrane Handbook for Systematic Reviews of Interventions. ${ }^{10}$ Although many databases exist, we focused on the Cochrane Library because our study objective was to specifically review RCTs examining the effectiveness of phone reminders for improving adherence to ART regimens. The guidelines presented by the Cochrane Collaboration are often regarded as the gold standard for performing meta-analytic reviews. Interestingly, when compared with matched Cochrane reviews, a study found that non-Cochrane reviews showed significantly higher effect sizes and lower precision, based on a matched-pair analysis. ${ }^{11}$ Furthermore, an adequate review has been shown to be attainable by searching a single database. ${ }^{12-14}$ Data was searched using the patient, intervention, comparison, and outcome (PICO) search strategy. ${ }^{15}$ The identified keywords, based on medical subheading $(\mathrm{MeSH})^{16}$ terms, were the following:

(anti*retroviral* OR "post*exposure prophylaxis" OR "post*exposure prevention*") AND ("mobile phone*" OR smartphone* OR "cell phone*" OR telephone* OR "mobile telephone*" OR phone* OR "cell* phone*" OR "cell* telephone*") AND (adhere* OR compliance).

A broad search symbol, such as the asterisk (*), was used to ensure the inclusion of all relevant studies. The inclusion criteria for the study selection were as follows: (a) clinical trial; (b) phone as intervention; and (c) outcome reported regarding ART adherence. The exclusion criteria for this review were as follows: (a) review; (b) no intervention; (c) abstract or conference proceedings; (d) not related to ART; (e) no full article; (f) not in English; (g) study protocol or ongoing trials; (h) included other equipment or mobile applications for pill counting; and (i) interventions were combined with other non-phone related or behaviour-related interventions. Irrelevant studies were eliminated.

\section{Selection of Studies}

During the initial stage, search results were imported into a bibliographic citation management software (EndNote X8). Duplicate references were removed before the authors selected potential papers for inclusion. This process was divided into three phases, during which the articles were screened, first by title, then by abstract, and finally, the whole text was reviewed for relevance. Article selection was 
performed based on the Preferred Reporting Items for Systematic Reviews and Meta-Analyses (PRISMA) study flow diagram; ${ }^{17}$ as outlined in Figure 1. First, the titles of the articles were screened for relevance and duplication. Next, the abstracts and whole texts for each selected article were critically reviewed and appraised. Articles that have combine interventions (non-phone related or behaviour-related interventions) were excluded as they may influence the outcome of adherence being studied. Blinded article selection was performed by two reviewers, a student of Doctor of Public Health (AAAW) and his lecturer (HI), at Universiti Kebangsaan Malaysia (UKM).

\section{PRISMA 2009 Flow Diagram}
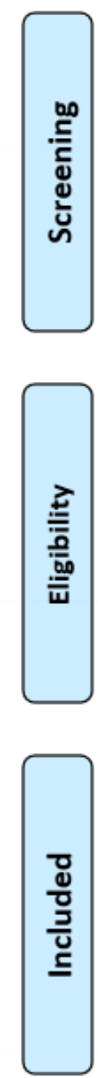
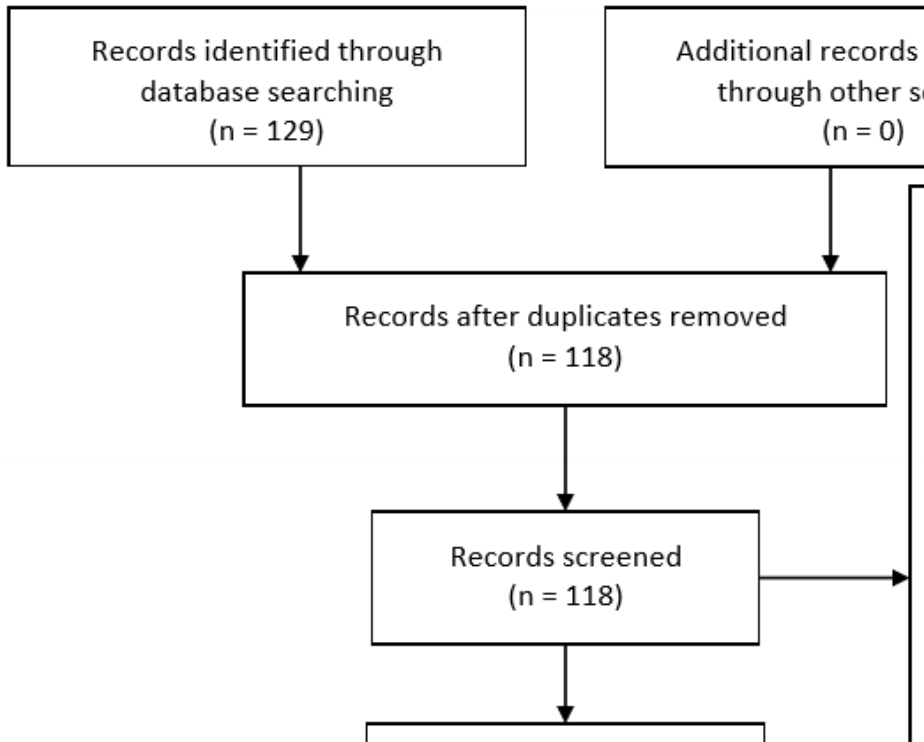

Full-text articles assessed

for eligibility $(n=26)$

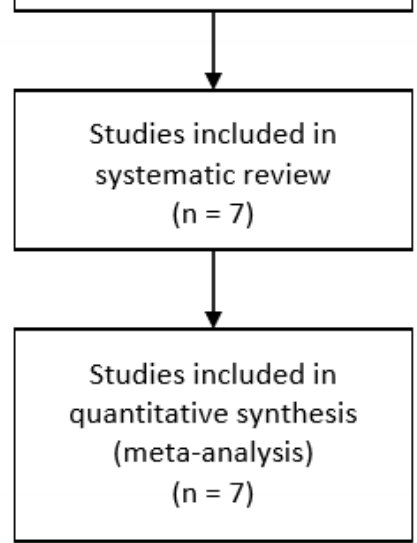

Articles excluded $(\mathrm{n}=92)$

Reasons:

1) Full text not available $=9$

2) Abstract/Conference

Proceedings $=10$

3) Correspondence $=1$

4) Erratum = 1

5) No quantitative data $=3$

6) Not measuring outcome of interest $=10$

7) Different intervention $=7$

8) Protocol study $=42$

9) Study terminated $=3$

10) Not trials $=6$

Articles excluded $(n=19)$

Reasons:

1) Combined intervention $=17$

2) Not measuring outcome of interest $=1$

3) Insufficient information = 1

Figure 1 Process of Study Selection.

Operational Variable Definition

In this study, we included RCTs that assessed adherence in terms of taking medications and attending follow-up visits. Adherence outcomes were measured either via follow-up rate, the proportion of prescribed medications taken by patients, or the total score on an adherence questionnaire. 


\section{Data Extraction}

Data extraction pertaining to adherence (follow-up rate, the proportion of prescribed medications taken by patients, or the total score on adherence questionnaire) was performed by two authors (AAAW, HI), independently, using a predetermined data collection form. The data was then crossed checked by both authors to minimise errors. In case of dispute between two authors, reconciliation meeting was being exercised.

Risk of Bias Assessment

The risk of bias assessment was performed using the latest Cochrane methods for assessing the risk of bias, which were described in the Cochrane Handbook, version 5.1.0. ${ }^{10}$ According to the guidelines described by the handbook, Grades of Recommendation, Assessment, Development, and Evaluation (GRADE) approach was applied to assess the quality of evidence and to prepare summary of findings tables, using the GRADEpro Guideline Development Tool application. ${ }^{18}$

Data synthesis

Data synthesis was performed using Review Manager 5.2, ${ }^{19}$ and, where appropriate, we combined studies using a fixed-effects model. Results were calculated using a risk ratio (RR), with a $95 \%$ confidence interval $(\mathrm{CI})$, and a p-value $<0.05$ was considered to be significant. Funnel plots were used to assess publication bias by plotting the effect sizes and trial sizes.

Statistical heterogeneity was assessed by inspecting forest plots for overlapping confidence intervals, applying the $\chi^{2}$ test ( $p$-value $<0.10$ was considered to be statistically significant) and the $\mathrm{I}^{2}$ statistic ( $\mathrm{I}^{2}$ value of $50 \%$ was used to denote moderate levels of heterogeneity). If heterogeneity was detected and if we still considered combining studies to be clinically meaningful, we used a random-effects model. Sensitivity analysis was performed to determine which factors contributed to high heterogenicity.

Our meta-analysis of the data on adherence, based on the proportion of prescribed pills taken, showed great heterogeneity. Therefore, we decided to perform subgroup analyses based on the number of phone interventions that were delivered to subjects (single/combined). Three articles were examined for the sub-group analysis of studies that examined the effects of single intervention. Two articles were included in the subgroup analysis performed for articles that utilised combined interventions, both of them provided two phone interventions to the subjects. Other metaanalyses were performed on adherence data that were based on questionnaire scores and follow-up attendance.

\section{RESULTS}

Descriptive Analysis

Seven RCTs were included in this review, published between the years 2010 and 2017..$^{20-26}$ The sample size ranged from 76 participants to 631 participants. Five of the RCTs used either short messages service (SMS) and phone call reminders as interventions. ${ }^{20-}$ 24 Two studies ${ }^{25,26}$ used combined interventions, both through the phones, with one study using automated voice reminders and pictorial messages, whereas the other study used SMS and phone call reminders. All included RCTs were performed in lower-middle-, upper-middle- and high-income Countries. ${ }^{27}$ A summary of all studies included is shown in Table 1.

Table 1 Summary of the Included Studies

\begin{tabular}{|c|c|c|c|c|c|}
\hline $\begin{array}{l}\text { Author } \\
\text { (year) }\end{array}$ & $\begin{array}{l}\text { Duration } \\
\text { (weeks) }\end{array}$ & Subjects & $\begin{array}{l}\text { Intervention } \\
\text { (Single / Combined) }\end{array}$ & Outcome & Country \\
\hline $\begin{array}{l}\text { Lester } \\
(2010)^{20}\end{array}$ & 24 & 538 & $\begin{array}{l}\text { Single; } \\
\text { SMS }\end{array}$ & $\begin{array}{l}\text { Proportion of prescribed pills } \\
\text { taken }\end{array}$ & Kenya \\
\hline $\begin{array}{l}\text { Uzma } \\
(2011)^{21}\end{array}$ & 10 & 76 & $\begin{array}{l}\text { Single; } \\
\text { Phone call }\end{array}$ & $\begin{array}{l}\text { Proportion of prescribed pills } \\
\text { taken }\end{array}$ & Pakistan \\
\hline $\begin{array}{l}\text { Mbuagbaw } \\
(2012)^{22}\end{array}$ & 24 & 200 & $\begin{array}{l}\text { Single; } \\
\text { SMS }\end{array}$ & $\begin{array}{l}\text { Proportion of prescribed pills } \\
\text { taken }^{\text {a }}\end{array}$ & Cameroon \\
\hline $\begin{array}{l}\text { Robbins } \\
(2013)^{23}\end{array}$ & 160 & 333 & $\begin{array}{l}\text { Single; } \\
\text { Phone call }\end{array}$ & Questionnaire Score & USA \\
\hline $\begin{array}{l}\text { Huang } \\
(2013)^{24}\end{array}$ & 12 & 93 & $\begin{array}{l}\text { Single; } \\
\text { Phone call }\end{array}$ & $\begin{array}{l}\text { 1) Questionnaire Score } \\
\text { 2) Follow-Up Attendance }\end{array}$ & Myanmar \\
\hline $\begin{array}{l}\text { Shet } \\
(2014)^{25}\end{array}$ & 96 & 631 & $\begin{array}{l}\text { Combined; } \\
\text { 1) Phone call } \\
\text { 2) Pictorial message }\end{array}$ & $\begin{array}{l}\text { Proportion of prescribed dose } \\
\text { taken }\end{array}$ & India \\
\hline $\begin{array}{l}\text { Abdul- } \\
\text { rahman } \\
(2017)^{26}\end{array}$ & 24 & 242 & $\begin{array}{l}\text { Combined; } \\
\text { 1) SMS } \\
\text { 2) Phone call }\end{array}$ & $\begin{array}{l}\text { 1) Proportion of prescribed } \\
\text { pills taken } \\
\text { 2) Questionnaire Score } \\
\text { 3) Follow-Up Attendance }\end{array}$ & Malaysia \\
\hline
\end{tabular}

${ }^{a}$ Visual Analogue Scale 
Abbreviation:

USA - United States of America

Meta-Analysis

Adherence Based on the Proportion of Prescribed Pills Taken

Five RCTs reported adherence outcomes based on the proportion of prescribed pills taken. ${ }^{20-}$ 22,25,26 Our analysis found that those who received any form of phone reminders had no difference in the likelihood of adherence than those who only received standard care $(\mathrm{RR}=1.18 ; 95 \% \mathrm{CI}, 0.95$, $1.46, \mathrm{Z}=1.51, \mathrm{p}=0.13$, Figure $2 \mathrm{a})$. The certainty of the evidence provided in these studies was graded Low via GRADEpro ${ }^{18}$ (Table II). All the five studies were heterogenous for measurements of adherence, based on the results of heterogeneity tests $\left(\chi^{2}=37.58\right.$, $\mathrm{df}=4, \mathrm{p}<0.001 ; \mathrm{I}^{2}=89 \%$, Figure $2 \mathrm{a}$ ).
Sub-Group Analysis: Adherence Based on the Proportion of Prescribed Pills Taken (Single Intervention)

Our analysis found that those who received single phone reminders had a $17 \%$ higher likelihood for adherence compared with those who did not receive any phone reminders intervention $(R R=1.17$, 95\%CI: $1.05,1.31)$, which was statistically significant $(Z=2.86, p=0.004)$. All three studies ${ }^{20-22}$ were homogenous for measuring similar outcomes, based on heterogeneity tests $\left(\chi^{2}=1.63, \mathrm{df}=2, \mathrm{p}=0.44\right.$; $\mathrm{I}^{2}=0 \%$, Figure $\left.2 \mathrm{~b}\right)$. The certainty of the evidence reported by these studies was graded High via GRADEpro $^{18}$ (Table 2).

a. Adherence Based on the Proportion of Prescribed Pills Taken (single and combined intervention)

\begin{tabular}{|c|c|c|c|c|c|c|c|c|c|}
\hline \multirow[b]{2}{*}{ Study or Subgroup } & \multicolumn{2}{|c|}{ Experimental } & \multicolumn{2}{|c|}{ Control } & \multirow[b]{2}{*}{ Weight } & \multirow{2}{*}{$\begin{array}{c}\text { Risk Ratio } \\
\text { M-H, Random, } 95 \% \mathrm{Cl}\end{array}$} & \multirow{2}{*}{\multicolumn{3}{|c|}{$\begin{array}{c}\text { Risk Ratio } \\
\text { M-H, Random, } 95 \% \mathrm{Cl}\end{array}$}} \\
\hline & Events & Total & Events & Total & & & & & \\
\hline Abdulrahman 2017 & 107 & 116 & 59 & 108 & $19.6 \%$ & $1.69[1.41,2.02]$ & & -- & \\
\hline Lester 2010 & 168 & 273 & 132 & 265 & $20.4 \%$ & $1.24[1.06,1.44]$ & & $\rightarrow$ & \\
\hline Mbuagbaw 2012 & 72 & 101 & 66 & 99 & $19.4 \%$ & $1.07[0.89,1.29]$ & & & \\
\hline Shet 2014 & 219 & 300 & 234 & 299 & $21.9 \%$ & $0.93[0.85,1.02]$ & & & \\
\hline Uzma 2011 & 30 & 34 & 27 & 34 & $18.6 \%$ & $1.11[0.90,1.37]$ & & - & \\
\hline Total $(95 \% \mathrm{Cl})$ & & 824 & & 805 & $100.0 \%$ & $1.18[0.95,1.46]$ & & & \\
\hline Total events & 596 & & 518 & & & & & & \\
\hline $\begin{array}{l}\text { Heterogeneity: Tau } \\
\text { Test for overall effec }\end{array}$ & $\begin{array}{l}0.05 ; \mathrm{Chi} \\
\mathrm{Z}=1.51\end{array}$ & $\begin{array}{l}=37.58 \\
=0.13)\end{array}$ & $d f=4($ & $P<0.0$ & $10001) ; l^{2}=$ & $=89 \%$ & $0.1 \quad 0.2$ & $\begin{array}{llr}0.5 & 1 & 2 \\
\text { rs [control] } & \text { Favours [ }\end{array}$ & \begin{tabular}{|l}
5 \\
5 \\
imental]
\end{tabular} \\
\hline
\end{tabular}

b. Adherence Based on the Proportion of Prescribed Pills Taken (Single Intervention)

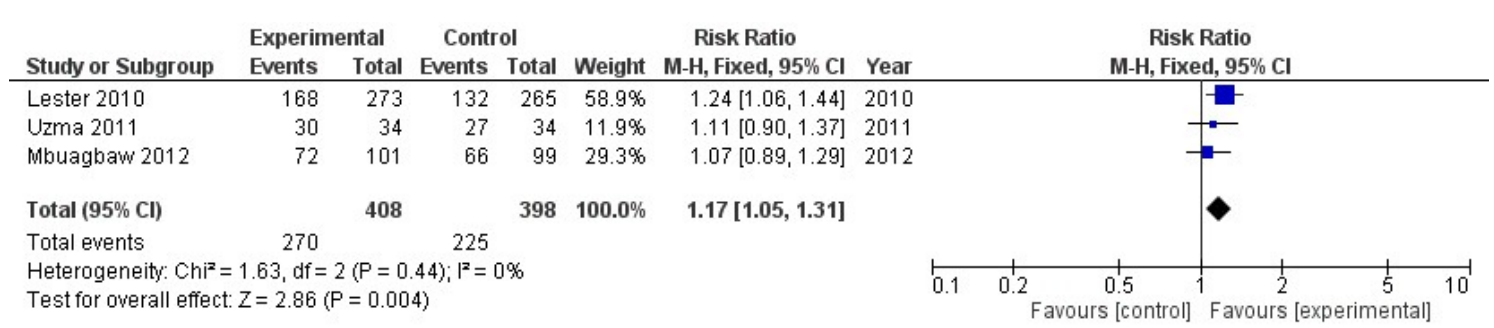

c. Adherence Based on Proportion of Prescribed Pills Taken (Combined Intervention)

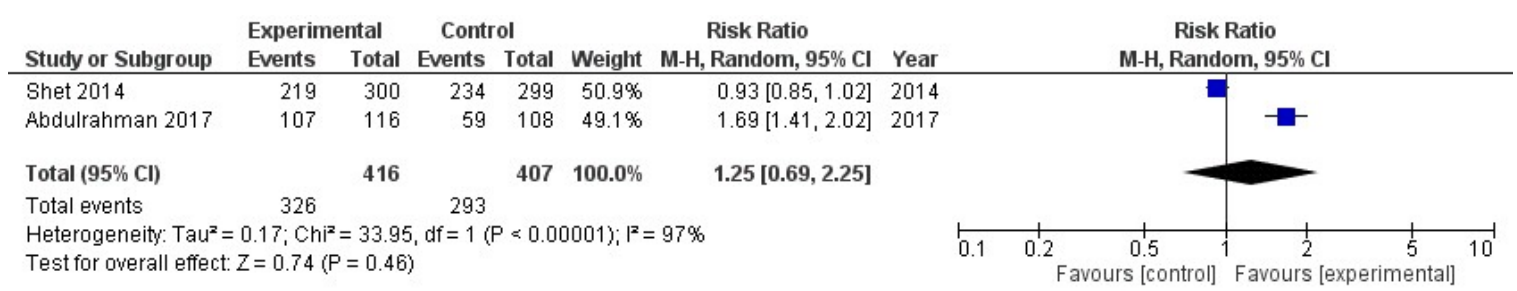

d. Adherence Based on Questionnaire Score 


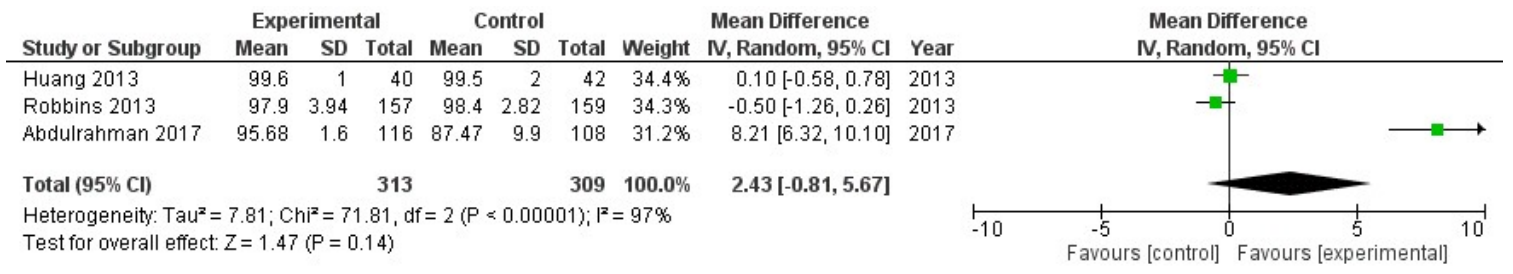

e. Adherence Based on Follow-Up Attendance

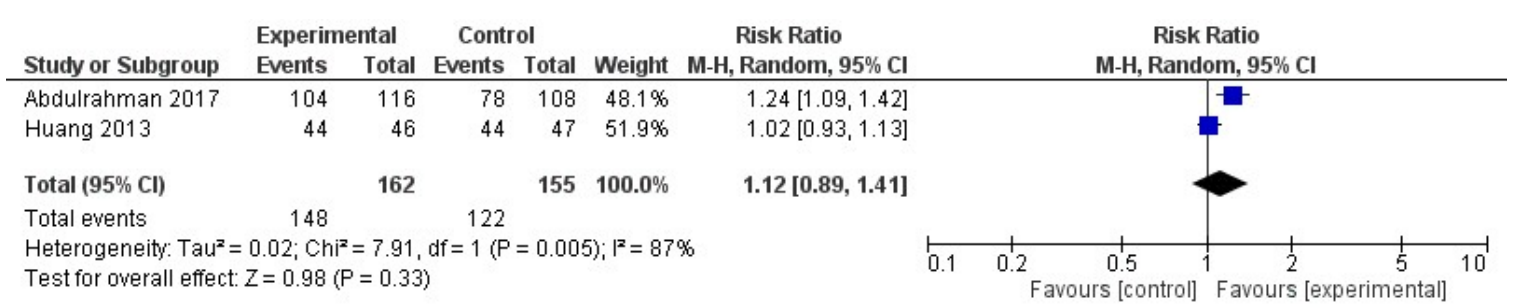

Figure 2 Meta-analysis results with forest plot and heterogeneity test comparing adherence based on prescribed pills taken (single and combined intervention, and single and combined intervention), questionnaire score and follow-up attendance

Sub-Group Analysis: Adherence Based on the Proportion of Prescribed Pills Taken (Combined Intervention)

Our analysis found that those who received combined forms of phone reminders had no difference in the likelihood for adherence than those who only received standard care $(\mathrm{RR}=1.25,95 \% \mathrm{CI}$ : $0.69,2.25, Z=0.74, p=0.46$ ). Neither studies ${ }^{25,26}$ was homogenous in measuring adherence, based on heterogeneity tests $\left(\chi^{2}=33.95, \quad \mathrm{df}=1, \quad \mathrm{p}<0.001\right.$; $\mathrm{I}^{2}=97 \%$, Figure $2 \mathrm{c}$ ). The certainty of evidence reported by these studies was graded Very Low via GRADEpro $^{18}$ (Table 2).

Adherence Based on Questionnaire Scores

Three RCTs reported adherence outcomes based on questionnaire scores. ${ }^{23,24,26}$ Our analysis found that those who received phone reminders had no difference in the likelihood of higher adherence scores compared with those who only received standard care [mean difference $(\mathrm{MD})=2.43,95 \% \mathrm{CI}$ : $-0.81,5.67, \mathrm{Z}=1.47, \mathrm{p}=0.14]$. These three studies were not homogenous in measuring similar outcomes, based on heterogeneity tests $\left(\chi^{2}=71.81\right.$, $\mathrm{df}=2, \mathrm{p}<0.001 ; \mathrm{I}^{2}=97 \%$, Figure $2 \mathrm{~d}$ ). The certainty of the evidence reported by these studies was graded High via GRADEpro ${ }^{18}$ (Table 2).

Adherence Based on Follow-Up Attendance Two RCTs reported adherence outcomes based on follow-up attendance. ${ }^{24,26}$ Our analysis found that those who received phone reminders had no difference in the likelihood of adherence compared with those who only received standard care $(\mathrm{RR}=1.12,95 \% \mathrm{CI}: 0.89,1.41, \mathrm{Z}=0.98, \mathrm{p}=0.33)$. These studies were not homogenous in measuring similar outcomes, based on heterogeneity tests $\left(\chi^{2}=7.91, \mathrm{df}=1, \mathrm{p}=0.005 ; \mathrm{I}^{2}=87 \%\right.$, Figure $\left.2 \mathrm{e}\right)$.

Table 2 GRADEpro Summary of Findings (Phone reminder intervention compared with no phone reminder intervention for improving adherence to anti-retroviral therapy regimens)

\begin{tabular}{|c|c|c|c|c|c|}
\hline Outcomes & No. of & Certainty of the & Relative & \multicolumn{2}{|c|}{ Anticipated absolute effects } \\
\hline & $\begin{array}{l}\text { pant } \\
\text { (studies) }\end{array}$ & (GRADE) & $(95 \% \mathrm{CI})$ & $\begin{array}{l}\text { Risk with no } \\
\text { phone } \\
\text { reminder } \\
\text { intervention }\end{array}$ & $\begin{array}{l}\text { Risk } \\
\text { difference } \\
\text { with phone } \\
\text { reminder }\end{array}$ \\
\hline $\begin{array}{l}\text { Adherence Based on the } \\
\text { Proportion of Prescribed } \\
\text { Pills Taken }\end{array}$ & $\begin{array}{l}1629 \\
\text { (5 RCTs) }\end{array}$ & $\begin{array}{l}\oplus \oplus \bigcirc \bigcirc \\
\mathrm{LOW}^{\mathrm{a}, \mathrm{b}}\end{array}$ & $\begin{array}{l}\text { RR } 1.18 \\
(0.95 \text { to } \\
1.46)\end{array}$ & 643 per 1,000 & $\begin{array}{l}116 \text { more per } \\
1,000 \\
(32 \text { fewer to } \\
296 \text { more })\end{array}$ \\
\hline $\begin{array}{l}\text { Sub-Group Analysis: } \\
\text { Adherence Based on the } \\
\text { Proportion of Prescribed } \\
\text { Pills Taken (Single } \\
\text { Intervention) }\end{array}$ & $\begin{array}{l}806 \\
\text { (3 RCTs) }\end{array}$ & $\begin{array}{l}\oplus \oplus \oplus \oplus \\
\mathrm{HIGH}\end{array}$ & $\begin{array}{l}\text { RR } 1.17 \\
(1.05 \text { to } \\
1.31)\end{array}$ & 565 per 1,000 & $\begin{array}{l}96 \text { more per } \\
1,000 \\
(28 \text { more to } \\
175 \text { more })\end{array}$ \\
\hline
\end{tabular}


Sub-Group Analysis: Adherence Based on the Proportion of Prescribed Pills Taken (Combined Intervention)
823

(2 RCTs)

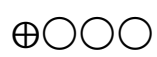

VERY LOW ${ }^{\mathrm{c}, \mathrm{d}, \mathrm{e}}$

RR 1.25

(0.69 to

2.25)

$\mathrm{MD} 2.43$

$(-0.81$ to

5.67)

622

(3 RCTs)

$\bigoplus \oplus \bigoplus \oplus$

$\mathrm{HIGH}$
Aherence Based on

Questionnaire Score

(2 RCTs)

Follow-up Attendance $\oplus \oplus \oplus \bigcirc$ MODERATE
RR 1.12

(0.89 to

1.41)
180 more per

1,000

(223 fewer to

900 more)

The mean

adherence MD 2.43

Based on higher

Question- (0.81 lower to

naire Scores $\quad 5.67$ higher)

was 0

94 more per

1,000

787 per 1,000

(87 fewer to

323 more)

Abbreviations: CI: Confidence interval; RR: Risk ratio; MD: Mean difference

The certainty of the evidence reported by these studies was graded Moderate via GRADEpro ${ }^{18}$ (Table 2).

${ }^{a}$ Different outcome measurements for adherence across studies

Indirect intervention

${ }^{a}$ Evidence of publication bias, as determined by plots that fell outside of the effective zone

${ }^{a}$ Different intervention being applied, with a different adherence measurement tool being used

andirect outcome measured

a Total number of events was less than 300 (rule of thumb)

\section{DISCUSSION}

Several types of adherence outcomes were measured in the studies included in our meta-analysis. Most of the studies measured adherence in terms of the proportion of prescribed medications taken. Only the study by Mbuagbaw et al., ${ }^{22}$ measured adherence using the Visual Analogue Scale, which was represented as adherence in terms of the proportion of prescribed medications taken for this study.

Majority of the articles had low risks of publication bias, as shown by funnel plots generated during the meta-analysis, except when examining two studies that used combined interventions, ${ }^{25,26}$ during sub-group analyses. Many adherence outcomes measured in this study were shown to be heterogenous, which is likely due to different operational definitions used for the adherence outcome measured and differences in the interventions given to the experimental groups being studied.

An analysis of five articles ${ }^{20-22,25,26}$ that gauged adherence based on the proportion of prescribed pills taken yielded high heterogeneity, primarily due to the interventions being delivered differently between studies. Three of these articles ${ }^{20-}$ 22 delivered only one type of intervention, whereas the other two articles ${ }^{25,26}$ delivered combined interventions.

During sub-group analyses, only adherence based on the proportion of prescribed pills taken after a single intervention yielded significant results. ${ }^{20-22}$ The certainty of the evidence reported by these studies was graded High via GRADEpro. ${ }^{18}$ Thus, we were able to conclude from this metaanalysis study that those who received a phone reminder had a $17 \%$ higher likelihood for adherence compared with those who did not receive a phone reminder intervention. This finding was consistent with the previous meta-analysis performed by Horvath et al., ${ }^{9}$ which found that weekly mobile phone text-messaging was effective for improving adherence to ART compared with standard care.

In this meta-analysis, our results suggested that phone reminders were a good method for improving adherence. This contemporary finding bears a close resemblance to the conventional information-motivation-behavioural (IMB) skills model described by Fisher et al. ${ }^{27}$ Phone reminders may serve as both the information and motivation arms that influence adherence behavioural skills and behaviour. For example, the reminder may contain information regarding the medication dose, sideeffects, and follow-up. Alternatively, social motivation may be gained from perceived social support for adherence, through phone calls, SMS, and pictorial messages.

Although SMS was thought to be the most common mode of communication, other technological advancements, such as WhatsApp and Snapchat, have also gained increasing popularity. ${ }^{28}$ Moreover, a separate study indicated that that the most popular form of social media for receiving messages was WhatsApp. ${ }^{29}$ Much evidence has supported the use of social media as stepping stones to improve adherence for medication and follow-up attendance among patients. For example, social media interventions using social applications and Facebook have resulted in significant improvements in adherence to HIV follow-up attendance. ${ }^{30}$ Similarly, other researchers found that social media 
forums improved adherence to medication regimens among patients with Systemic Lupus Erythematosus. $^{31}$

Although not significant, we reviewed the sub-group analysis examining adherence based on the proportion of prescribed pills taken with combined interventions further explore the contradictory findings reported by these RCTs compared with those studies that only used phone reminder interventions. On the one hand, those subjects who received automated voice reminders and pictorial messages had a $7 \%$ reduced likelihood for adherence compared with those who received standard care. ${ }^{25}$ On the other hand, those who received individualised SMS, combined with telephone call reminders, had a 69\% increased likely hood for adherence compared with those who received standard care. ${ }^{26}$ Comparatively, we can assume that a human touch was still valued to motivate adherence behaviour; therefore, receiving person-to-person communications as reminders, such as individualised SMS or phone calls, was shown to produce relatively better outcomes compared with automated reminders, which were assumed to have lost the invaluable human touch necessary to promote adherence.

Furthermore, although the meta-analyses consisted of High and Moderate certainty of evidence, respectively, further meta-analyses performed on adherence data based on questionnaire scores and follow-up attendance yielded no significant findings. We noticed that the validity of certain articles measuring adherence through selfreported questionnaire were questionable. Therefore, could be one of the reasons for nonsignificant finding in our meta-analysis. However, we continued to observe that the results were generally favourable, suggesting that phone reminders were an effective means for improving adherence. Such empirical evidence could obviously be seen in one local study by contemporary researcher that yield relatively large effect sized despite small number of participants, albeit rather ordinary intervention being delivered ${ }^{26}$.

When examined further, nearly all of the RCTs were performed on patients who were receiving first-line ART regimens. ${ }^{20-23,25,26}$ Although, significant improvements in ART adherence were observed in RCTs with study durations up to 12 months, ${ }^{23,26}$ increasing the study length to 160 weeks did not yield significant improvements in ART adherence. ${ }^{23}$ Moreover, weekly reminders yielded significant improvements for ART adherence, ${ }^{20,21,26}$ whereas RCTs using longer intervals between reminders, as long as every 8 weeks, did not yield significant improvements in ART adherence. ${ }^{23}$

Although nearly all of the RCTs were performed successfully, privacy issues remain a stumbling block, and one of the RCTs reported that one participant who was receiving motivational SMS messages withdrew from this study, citing loss of privacy. Previous privacy concerns have been discussed, as phone reminders may involve direct patient-provider communication. However, efforts can be made to reduce potential privacy concerns, such as coded messages. ${ }^{32}$

Likewise, the effectiveness of phone reminders may also be influenced by differences in HIV stigmatisation among the regions being studied. For example, Shet et al., ${ }^{25}$ raised the issue of stigmatisation risk among participants who received phone reminder interventions in India. However, another study performed in India found that stigma was not an issue among HIV patients. ${ }^{33}$

Of the seven RCTs included in this metaanalysis, two RCTs relied on SMS, three relied on phone calls, and two relied on both. However, the acceptance of these methods was only briefly mentioned. Differences in the method through which reminder interventions are delivered likely deserve further attention, as the desirability of person-to-person phone calls may vary generationally, and the generation referred to as "Millennials" are often described as disliking phone calls compared with older generations. ${ }^{34-36}$

In summary, phone reminders as interventions for improving adherence to ART regimens were shown to be beneficial. However, the reminder should be individualised, without neglecting the importance of human touch for the promotion of adherence. Advancements in technology can help improve adherence, without losing the human touch associated with soft-skills and communications during patient management among healthcare workers. The attitude of patients is also important for adherence behaviour with regards to medications and follow-up schedules.

In the future, careful consideration and proper evaluation of emerging technological advancements should be examined to determine whether social media be a promising approach for promoting patient adherence to ART regimens. We hope that the WHO's goal of "Getting to Zero: Zero new Human Immunodeficiency Virus (HIV) infections. Zero deaths from AIDS-related illness" maybe realised. ${ }^{2}$

\section{LIMITATIONS}

The limitation of this meta-analysis was that the adherence measured was based on different operational definition across study. In addition, the intervention also differed from study to study, as some RCTs was testing difference forms or methods of phone reminders. However, as these studies were considered clinically meaningful to be combined, random-effects model was used while in case if high heterogeneity detected, sub-group analysis was performed. 


\section{CONCLUSIONS}

The conclusions of this review should be interpreted with caution. On the one hand, the meta-analysis examining RCTs that delivered single interventions showed that interventions were effective when adherence was measured based on the proportion of prescribed pills taken. On the other hand, other meta-analyses referred here showed trends towards improved adherence that were not significant. These findings may add to the growing body of literature regarding adherence to ART regimens. We strongly believe that phone reminders remain an effective means of improving adherence to ART regimens. We hope that our findings may offer useful information to policymakers, who could consider phone reminders, as a means of intervention to improve adherence in the healthcare services.

\section{ACKNOWLEDGMENT}

We would like to thank the Director General of Health Malaysia for his permission to publish this article.

Funding Information

None.

Declaration of Conflicting Interests

The Authors declare that there is no conflict of interest.

Ethics approval

Ethics approval was obtained from the Ministry of Health Malaysia Medical Research \& Ethics Committee [NIH.800-4/4/1 Jld. 75(10)].

Consent

Not Applicable.

\section{REFERENCES}

1. World Health Organization. HIV/AIDS 2018 [cited Dec 2018]. Available from: https://www.who.int/news-room/factsheets/detail/hiv-aids.

2. World Health Organization. World AIDS Day 2012: Getting to Zero 2012 [cited Dec 2018]. Available from: https://www.who.int/hiv/events/2012/worl d_aids_day/en/.

3. Vella S, Schwartländer B, Sow SP, Eholie SP, Murphy RL. The history of antiretroviral therapy and of its implementation in resource-limited areas of the world. AIDS 2012; 26(10): 1231-41.

4. World Health Organization. Adherence to long-term therapies: Evidence for action 2003. [cited Dec 2018]. Available from: http://www.who.int/chp/knowledge/public ations/adherence_report/en/.

5. Cohen MS, Chen YQ, McCauley M, Gamble T, Hosseinipour MC,
Kumarasamy N, et al. Prevention of HIV-1 infection with early antiretroviral therapy. N Engl J Med. 2011; 365(6): 493-505.

6. Kashuba AD, Dyer JR, Kramer LM, Raasch RH, Eron JJ, Cohen MS. Antiretroviral-drug concentrations in semen: Implications for sexual transmission of human immunodeficiency virus type 1. Antimicrob Agents Chemother. 1999; 43(8): 1817-26.

7. Robbins RN, Spector AY, Mellins CA, Remien RH. Optimizing ART Adherence: Update for HIV Treatment and Prevention. Curr HIV/AIDS Rep. 2014; 11(4): 423-33.

8. Chaiyachati KH, Ogbuoji O, Price M, Suthar AB, Negussie EK, Bärnighausen T. Interventions to improve adherence to antiretroviral therapy: A rapid systematic review. AIDS 2014; 28 Suppl 2: S187S204.

9. Horvath $\mathrm{T}$, Azman $\mathrm{H}$, Kennedy GE, Rutherford GW. Mobile phone text messaging for promoting adherence to antiretroviral therapy in patients with HIV infection. Cochrane Database Syst Rev. 2012; (3): CD009756.

10. Higgins J, Green S, editors. Cochrane Handbook for Systematic Reviews of Interventions. Version 5.1.0. The Cochrane Collaboration 2011 [cited Dec 2018]. Available from: https://handbook-51.cochrane.org.

11. Useem J, Brennan A, LaValley M, Vickery M, Ameli O, Reinen N, et al. Systematic differences between cochrane and noncochrane meta-analyses on the same topic: A matched pair analysis. PLoS One. 2015; 10(12): e0144980.

12. Van Enst WA, Scholten RJPM, Whiting P, Zwinderman AH, Hooft L. Metaepidemiologic analysis indicates that MEDLINE searches are sufficient for diagnostic test accuracy systematic reviews. J Clin Epidemiol 2014; 67(11): 1192-9.

13. Rice DB, Kloda LA, Levis B, Qi B, Kingsland E, Thombs BD. Are MEDLINE searches sufficient for systematic reviews and meta-analyses of the diagnostic accuracy of depression screening tools? A review of meta-analyses. J Psychosom Res. 2016; 87: 7-13.

14. Bramer WM, Rethlefsen ML, Kleijnen J, Franco OH. Optimal database combinations for literature searches in systematic reviews: A prospective exploratory study. Syst Rev. 2017; 6(1): 245.

15. Jacobs SK. Research Guides: Health (Nursing, Medicine, Allied Health): Search 
Strategies: Framing the question (PICO) 2019 [cited Dec 2018]. Available from: https://guides.nyu.edu/c.php?g=276561\&p $=1847897$.

16. Cochrane. Medical terms (MeSH) 2019 [cited Dec 2018]. Available from: https://www.cochranelibrary.com/advance $\mathrm{d}$-search/mesh.

17. Moher D, Liberati A, Tetzlaff J, Altman DG, Altman G. Preferred reporting items for systematic reviews and meta-analyses : the PRISMA statement. BMJ 2009; 339: b2535.

18. GRADEpro GDT: GRADEpro Guideline Development Tool [Software]. McMaster University 2015 (developed by Evidence Prime, Inc.). Available from: gradepro.org.

19. Review Manager (RevMan) [Computer program]. Version 5.3. Copenhagen: The Nordic Cochrane Centre, The Cochrane Collaboration 2014.

20. Lester RT, Ritvo P, Mills EJ, Kariri A, Karanja S, Chung MH, et al. Effects of a mobile phone short message service on antiretroviral treatment adherence in Kenya (WelTel Kenya1): A randomised trial. Lancet. 2010; 376(9755): 1838-45.

21. Uzma Q, Emmanuel F, Ather U, Zaman S. Efficacy of interventions for improving antiretroviral therapy adherence in HIV/AIDS cases at PIMS, Islamabad. J Int Assoc Physicians AIDS Care. 2011; 10(6): 373-83.

22. Mbuagbaw L, Thabane L, Ongolo-Zogo P, Lester RT, Mills EJ, Smieja M, et al. The Cameroon Mobile Phone SMS (CAMPS) Trial: A Randomized Trial of Text Messaging versus Usual Care for Adherence to Antiretroviral Therapy. PLoS One. 2012; 7(12): e46909.

23. Robbins GK, Testa MA, Su M, Safren SA, Morse G, Lammert S, et al. Site NurseInitiated Adherence and Symptom Support Telephone Calls for HIV-Positive Individuals Starting Antiretroviral Therapy, ACTG 5031: Substudy of ACTG 384. HIV Clin Trials. 2013; 14(5): 235-53.

24. Huang D, Sangthong R, McNeil E, Chongsuvivatwong V, Zheng W, Yang X. Effects of a Phone Call Intervention to Promote Adherence to Antiretroviral Therapy and Quality of Life of HIV/AIDS Patients in Baoshan, China: A Randomized Controlled Trial. AIDS Res Treat. 2013; 2013: 580974.

25. Shet A, De Costa A, Kumarasamy N, Rodrigues R, Rewari BB, Ashorn P, et al. Effect of mobile telephone reminders on treatment outcome in HIV: Evidence from a randomised controlled trial in India. BMJ.
2014; 349: g5978.

26. Abdulrahman SA, Rampal L, Ibrahim F, Radhakrishnan AP, Kadir Shahar H, Othman N. Mobile phone reminders and peer counseling improve adherence and treatment outcomes of patients on ART in Malaysia: A randomized clinical trial. PLoS One. 2017; 12(5): e0177698.

27. Fisher JD, Fisher WA, Amico KR, Harman JJ. An information-motivation-behavioral skills model of adherence to antiretroviral therapy. Health Psychol. 2006; 25(4): 462473.

28. Mills EJ, Lester RT. Mobile phone-enabled adherence in HIV/AIDS. Lancet Digit Health. 2019; 1(1): e4-e5.

29. Stankievich E, Malanca A, Foradori I, Ivalo S, Losso M. Utility of Mobile Communication Devices as a Tool to Improve Adherence to Antiretroviral Treatment in HIV-infected Children and Young Adults in Argentina. Pediatr Infect Dis J. 2018; 37(4): 345-8.

30. Tanner AE, Song EY, Mann-Jackson L, Alonzo J, Schafer K, Ware S, et al. Preliminary Impact of the weCare Social Media Intervention to Support Health for Young Men Who Have Sex with Men and Transgender Women with HIV. AIDS Patient Care STDS. 2018; 32(11): 450-8.

31. Sadun RE, Schanberg LE. Using social media to promote medication adherence. Nat Rev Rheumatol. 2018; 14(8): 445-6.

32. Kunutsor S, Walley J, Katabira E, Muchuro S, Balidawa H, Namagala E, et al. Using mobile phones to improve clinic attendance amongst an antiretroviral treatment cohort in rural Uganda: A cross-sectional and prospective study. AIDS Behav. 2010; 14(6): 1347-52.

33. Sidney K, Antony J, Rodrigues R, Arumugam K, Krishnamurthy S, D’Souza $\mathrm{G}$, et al. Supporting patient adherence to antiretrovirals using mobile phone reminders: Patient responses from South India. AIDS Care. 2012; 24(5): 612-7.

34. Andy Meek. A bunch of millennials explained in a survey why they despise phone calls 2018 [cited Dec 2019]. Available from: https://bgr.com/2018/12/09/millennialsphone-calls-survey/.

35. Wiest B. Millennials Hate Phone Calls, And They Have A Point 2019 [cited Dec 2019]. Available from: https://www.forbes.com/sites/briannawiest /2019/11/04/millennials-hate-phone-callsthey-have-a-point/\#c121325517ec.

36. Brandon J. Why Millennials Don't Like to Make Phone Calls 2017 [cited Dec 2019]. 
International Journal of Public Health Research Vol 11 No 2 2021, pp (1407-1417)

Available from: http://www.inc.com/johnbrandon/why-millennials-dont-like-tomake-phone-calls.html. 